\title{
Unmet Needs in LDL-C Lowering: When Statins Won't Do!
}

\author{
Stephan Krähenbühl $^{1,2}$ • Ivana Pavik-Mezzour ${ }^{5}$ - Arnold von Eckardstein ${ }^{3,4}$
}

Published online: 25 July 2016

(c) The Author(s) 2016. This article is published with open access at Springerlink.com

\begin{abstract}
The use of low-density lipoprotein cholesterol (LDL-C)-lowering medications has led to a significant reduction of cardiovascular risk in both primary and secondary prevention. Statin therapy, one of the cornerstones for the prevention and treatment of cardiovascular disease (CVD), has been demonstrated to be effective in lowering LDL-C levels and in reducing the risk for CVD and is generally well-tolerated. However, compliance with statins remains suboptimal. One of the main reasons is limitations by adverse events, notably myopathies, which can lead to non-compliance with the prescribed statin regimen. Reducing the burden of elevated LDL-C levels is critical in patients with CVD as well as in patients with very high baseline levels of LDL-C (e.g. patients with familial hypercholesterolaemia), as statin therapy is insufficient for optimally reducing LDL-C below target values. In this review, we discuss alternative treatment options after maximally
\end{abstract}

Stephan Krähenbühl

stephan.kraehenbuehl@usb.ch

Ivana Pavik-Mezzour

ipavik@amgen.com

Arnold von Eckardstein

arnold.voneckardstein@usz.ch

1 Division of Clinical Pharmacology and Toxicology, University Hospital, Basel, Switzerland

2 Department of Clinical Research, University of Basel, Basel, Switzerland

3 Institute of Clinical Chemistry, University Hospital Zürich, Zurich, Switzerland

4 Zürich Center for Integrative Human Physiology, University of Zürich, Zurich, Switzerland

5 Amgen Switzerland AG, Dammstrasse 21, 6301 Zug, Switzerland tolerated doses of statin therapy, including ezetimibe, proprotein convertase subtilisin/kexin type 9 (PCSK9) inhibitors, and cholesteryl ester transfer protein (CETP) inhibitors. Difficult-to-treat patients may benefit from combination therapy with ezetimibe or a PCSK9 inhibitor (evolocumab or alirocumab, which are now available). Updates of treatment guidelines are needed to guide the management of patients who will best benefit from these new treatments.

\section{Key Points}

Although statins have proven to be a valuable and efficacious low-density lipoprotein cholesterol (LDL-C)-lowering medication, they may not be sufficient or appropriate for every patient in need.

Some patients may benefit from additional or alternative approaches for LDL-C lowering, particularly those with familial hypercholesterolaemia and other patients in whom LDL-C lowering is not sufficient or who are intolerant to statins.

Alternative therapies should be considered for patients who do not reach their LDL-C target, for example, ezetimibe or proprotein convertase subtilisin/kexin type 9 (PCSK9) inhibitors.

\section{Introduction}

Cardiovascular disease (CVD) is the main cause of death in Europe, accounting for over 4 million deaths each year [1]. Nearly half $(47 \%)$ of all deaths are from CVD (52\% of 
deaths in women and $42 \%$ in men). Just under half of all deaths from CVD in both men and women are from coronary heart disease (CHD), while stroke accounts for nearly one-third of deaths in women and one-quarter of deaths in men [1]. CVD has major economic and human costs: overall, it is estimated to cost the EU economy almost $€ 196$ billion a year. Of the total cost of CVD in the $\mathrm{EU}$, around $54 \%$ is due to direct healthcare costs, $24 \%$ to productivity losses, and $22 \%$ to the informal care of people with CVD [1].

The role of low-density lipoprotein cholesterol (LDL-C) in the pathophysiology of CVD is acknowledged and wellunderstood, and the use of LDL-C-lowering medications has led to a significant reduction of cardiovascular risk in both primary and secondary prevention. Notably, statin therapy has become a cornerstone for the prevention and treatment of CVD, and is generally safe and well-tolerated [2]. A number of large-scale clinical trials have demonstrated that statins substantially reduce cardiovascular morbidity and mortality in both primary and secondary prevention [3-7] and in high-risk patients [8]. Statins have also been shown to slow the progression or even promote regression of coronary atherosclerosis [9].

However, compliance remains suboptimal, even though long-term persistence with statin therapy is important for clinical benefits [10]. Moreover, in many patients, treatment with statin therapy is insufficient to optimally reduce LDL-C below target values. The most important reasons are very high baseline levels of LDL-C, for example in patients with familial hypercholesterolaemia $(\mathrm{FH})$, and that the adverse effects of statin therapy can pose limitations, notably myopathies, which can lead to non-compliance with the prescribed statin regimen. Reducing the burden of elevated LDL-C levels is critical in these difficult-to-treat patient groups and there is a need for new treatment options and/or combination therapies that ultimately translate into improved clinical outcomes.

\section{Treatment Aims and Low-Density Lipoprotein Cholesterol (LDL-C) Targets}

LDL-C is the primary target of dyslipidemia management; it is tightly linked to outcomes and is therefore a reliable and widely used surrogate parameter. The 2010 Cholesterol Treatment Trialists' (CTT) Collaboration meta-analysis, which included 21 randomized trials of statin versus control in almost 130,000 patients and five trials of more versus less intensive statin regimens in almost 40,000 patients, confirmed a dose-dependent reduction in CVD with LDL-C lowering [3]. Among available statin therapies, more intensive regimens resulted in a significant further proportional $15 \%$ risk reduction in major vascular events associated with the mean $0.51 \mathrm{mmol} / 1$ further LDL-C reduction. In the meta-analysis of statin versus control, there was a significant risk reduction of $22 \%$ with a $1.00 \mathrm{mmol} / \mathrm{l}$ LDL-C reduction. The most recent CTT meta-analysis, which focused on whether statin therapy is as effective in women as in men, found similar effectiveness for the prevention of major vascular events in both groups [5].

Target levels of LDL-C are defined by the patient's cardiovascular risk. All current guidelines on the prevention of CVD in clinical practice recommend the assessment of clinically manifest atherosclerotic CVD and cardiovascular risk because, in most people, atherosclerotic CVD is the product of a number of risk factors [2]. In primary prevention, many risk assessment systems are available, including Framingham, Systemic Coronary Risk Estimation (SCORE), Q-Risk, Prospective Cardiovascular Munster Study (PROCAM), the American Heart Association (AHA)/American College of Cardiology (ACC) Pooled Cohort Equations, and the World Health Organization (WHO) [11-13]. Most guidelines use risk estimation systems based on either the Framingham or the SCORE projects $[2,14,15]$. The SCORE system estimates the 10-year risk of a first fatal atherosclerotic event, whether heart attack, stroke, or other occlusive arterial disease, including sudden cardiac death. According to the European guidelines [2], the presence of atherosclerotic CVD, e.g. a history of acute myocardial infarction or stroke (i.e. secondary prevention), defines an LDL-C target $<1.8 \mathrm{mmol} / 1$ ( $70 \mathrm{mg} /$ dl). In primary prevention of patients with diabetes mellitus (T2DM), FH, or multiple risk factors leading to the estimation of high cardiovascular risk, an LDL-C level $<2.6 \mathrm{mmol} / \mathrm{l}(100 \mathrm{mg} / \mathrm{dl})$ should be targeted. If these absolute treatment goals are not reached, LDL-C levels should be at least halved.

The recent American guidelines (AHA/ACC 2013) no longer foresee any absolute target levels of LDL-C, but recommend using high-intensity statin treatment to reduce LDL-C levels by $\geq 50 \%$ in patients with manifest atherosclerotic disease or high estimated risk, and to reduce LDL-C levels by $30-50 \%$ in patients with moderate risk. Their new Pooled Cohort Equations risk calculator results in a larger population qualifying for treatment with statins, which has been a matter of debate [16, 17]. If more patients commence statin therapy because of an overestimated risk, this might be a reason for more cases of statin non-adherence due to treatment-related adverse effects [18].

\section{Statin Non-Adherence and Intolerance}

Despite the evidence that low adherence to statins is linked with worsening outcomes [19-21], numerous studies have documented high rates of non-adherence to statins [22, 23]. 
It is estimated that about half of patients discontinue statin therapy within the first year of treatment, with further decreases in adherence over time [24]. There are many reasons for non-adherence, including age, sex, income, comorbidities, and complexity of regimen [24]. Using clinical judgment alone, physicians are poor at identifying which patients have problems with adherence [25]. From a patient perspective, concerns about the adverse effects of statins are a dominant theme [26, 27]. Statin-related adverse effects include mainly muscle symptoms, but also headache, sleep disorders, dyspepsia, nausea, rash, alopecia, erectile dysfunction, gynecomastia, and/or arthritis [28]. Statin use has also been associated with an increased risk of T2DM [29-31]. Additionally, disparities in lipid control among patients with T2DM using statins have been reported [32]. Data reported from the PINNACLE registry showed that patients with T2DM were less likely to achieve LDL-C and non-high-density lipoprotein cholesterol (non-HDL-C) goals than other patients with dyslipidemia. Goals were not achieved for nearly $70 \%$ of patients [33].

Most common adverse effects associated with statins are muscle related [28], and the most recent statement from the European Atherosclerosis Society (EAS) uses the term statin-associated muscle symptoms (SAMS) [34]. SAMS are one of the principal reasons for statin non-adherence and/or discontinuation, contributing to adverse cardiovascular outcomes [34].

The clinical features of SAMS include symptoms such as muscle aches or myalgia, weakness, stiffness, and cramps [35]. SAMS are usually defined as diffuse muscle symptoms that may or may not be accompanied by an elevation of plasma creatinine kinase (CK) activity $[35,36]$. Rhabdomyolysis is a more severe form of statininduced myopathy (usually associated with CK elevations $>10$ times the upper limit of normal [ULN]), resulting in severe skeletal muscle injury, lysis, and excretion of dark brown urine, indicating the presence of excess myoglobin and leading to kidney damage [37, 38].

It is estimated that SAMS occur in $2-6 \%$ of the statin population (affecting about 1 million patients) [39] based on real-world data, the incidence rate of SAMS is approximately 5-10\% [40, 41]. Patient registries and clinical experience estimate the incidence of SAMS at between 7 and $29 \%$, and these may be an important contributor to the very high discontinuation rates observed with statin therapy [34, 40, 42-45]. In their investigation of long-term persistence with statin treatment, Chodick et al. [10] found that $\geq 75 \%$ of patients discontinued therapy within 2 years of initiation.

The incidence of SAMS varies with different statins [28]. According to data from the PRIMO (Prediction of Muscular risk in Observational) and STOMP (Effects of Statins on Muscle Performance) studies, patients receiving simvastatin or atorvastatin are reported to be at the highest risk of SAMS (18.2 and 9.4-14.9\%, respectively) [40, 46]; patients receiving lovastatin might have a high risk of SAMS [28]; and the lowest rates are described for patients receiving pravastatin and fluvastatin (10.9 and $5.1 \%$, respectively) [40].

One possible explanation for the low risk of myopathy seen with pravastatin and fluvastatin may be because they are more hydrophilic and hence have less muscle penetration [28] (although this argument is weaker in the case of fluvastatin, which is relatively lipophilic). However, they are also least potent in LDL-C lowering, and statins associated with more aggressive LDL-C lowering might be expected to result in a higher risk of muscular adverse effects [40, 47].

Higher incidences of rhabdomyolysis were reported with atorvastatin or cerivastatin therapy, both as monotherapy and in combination with fibrates [48]. This was partially due to drug interactions with inhibitors of P450 cytochrome (CYP) 3A4, the main CYP involved in the hepatic metabolism of the lipophilic statins [49]. In addition, several researchers have found that concurrent use of statins with fibrates or niacin significantly increases the risk of rhabdomyolysis compared with monotherapy, with a higher risk more often reported in statin-fibrate combinations than in statin-niacin combinations [35, 37, 38]. These muscle effects have usually been reported with the use of synthetic, potent, and more lipophilic statins [35, 37, 38].

An important consideration is the increased likelihood of adverse effects with higher dose/potency statins. A review by Golomb and Evans [50] summarized evidence supporting a dose/potency dependence of statin adverse effects (Table 1).

Despite treatment guideline recommendations, low achievement rates of LDL-C targets are reported, and a large proportion (10-20\%) of high-risk and very high-risk patients still do not meet their target, particularly those who are not receiving high-potency statins $[39,55,56]$.

\section{Familial Hypercholesterolaemia}

$\mathrm{FH}$ is inherited as an autosomal dominant trait and is characterized by markedly elevated circulating levels of LDL-C from the time of birth as well as premature atherosclerotic CVD (ASCVD) [57-59]. With a prevalence of $1: 200$ [60] to $1: 500$ [61], heterozygous $\mathrm{FH}(\mathrm{HeFH})$ is very common. LDL-C levels in these patients are two- to threefold higher than normal [58, 59, 62, 63]. Homozygous FH $(\mathrm{HoFH})$ is very rare, affecting one in $300,000-1,000,000$ individuals [57, 64]. The paucity or even lack of any functional LDL receptors (LDLRs) leads 
Table 1 Evidence of dose/potency dependence of statin adverse events (adapted from Golomb and Evans [50])

\begin{tabular}{|c|c|c|}
\hline Study & $\mathrm{AE}$ & Comment \\
\hline Silva et al. [51] (meta-analysis of RCTs) & All AEs & $\begin{array}{l}\text { OR } 1.44 \text { (95\% CI } 1.33-1.55 ; p<0.001) \text { intensive- vs. } \\
\text { moderate-dose statin therapy }\end{array}$ \\
\hline Silva et al. [51] (meta-analysis of RCTs) & $\begin{array}{l}\text { AEs leading to } \\
\text { treatment } \\
\text { discontinuation }\end{array}$ & $\begin{array}{l}\text { OR } 1.28 \text { (95\% CI } 1.18-1.39 ; p<0.001) \text { intensive- vs. } \\
\text { moderate-dose statin therapy }\end{array}$ \\
\hline $\begin{array}{l}\text { Dale et al. [52] (meta-analysis of RCTs) } \\
\text { Silva et al. [51] (meta-analysis of RCTs) }\end{array}$ & CK elevation & $\begin{array}{l}\text { OR } 6.12 \text { (95\% CI 1.36-27.5) higher- vs. lower- dose statin } \\
\text { therapy (the odds appeared to be greater for lipophilic statins, } \\
\text { which have more muscle penetration) } \\
\text { OR } 9.97 \text { ( } 95 \% \text { CI } 1.3-77.9, p=0.028 \text { ) intensive- vs. } \\
\text { moderate-dose statin therapy }\end{array}$ \\
\hline $\begin{array}{l}\text { Dale et al. [52] (meta-analysis of RCTs) } \\
\text { Silva et al. [51] (meta-analysis of RCTs) }\end{array}$ & LFT elevation & $\begin{array}{l}\text { LFT (transaminase) elevation OR } 2.7(1.5-5.0) \text { higher- vs. } \\
\text { lower- dose statin therapy (the effect appeared to be greater } \\
\text { for hydrophilic statins } \\
\text { LFT elevation (alanine or aspartate aminotransferase } \geq 3 \text { times } \\
\text { the ULN) OR } 4.5 \text { ( } 95 \% \text { CI } 3.3-6.2 \text { ) intensive- vs. moderate- } \\
\text { dose statin therapy }\end{array}$ \\
\hline $\begin{array}{l}\text { SEARCH Collaborative Group [53] (randomized trial of } \\
12,064 \text { pts who received simvastatin } 20 \text { or } 80 \mathrm{mg} \\
\text { daily) }\end{array}$ & Rhabdomyolysis & $\begin{array}{l}49 \text { cases of 'definite myopathy' in the simvastatin } 80 \text {-mg group } \\
\text { vs. } 2 \text { in the simvastatin } 20 \text {-mg group. } 49 \text { cases of 'incipient } \\
\text { myopathy' in the simvastatin } 80 \text {-mg group vs. } 6 \text { in the } \\
\text { simvastatin } 20 \text {-mg group }\end{array}$ \\
\hline Golomb et al. [54] & $\begin{array}{l}\text { Non-CK elevating } \\
\text { muscle symptoms }\end{array}$ & $\begin{array}{l}\text { Recurrence of statin AEs was significantly higher when pts } \\
\text { were rechallenged with same or higher potency statins vs. } \\
\text { rechallenge with a lower potency statins ( } \sim 95 \text { vs. } 55 \% \text {, } \\
p<0.01 \text { ) }\end{array}$ \\
\hline
\end{tabular}

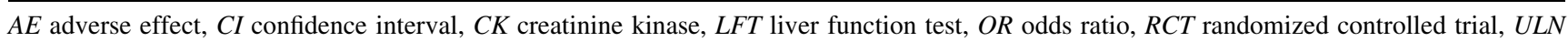
upper limit of normal

to LDL-C levels that are three- to sixfold higher than normal and a very early onset of atherosclerotic vascular disease, frequently in childhood or adolescence [58, 59, 62, 63]. Given the ASCVD complications associated with $\mathrm{FH}$, reducing the burden of elevated LDL-C levels is critical [57-60]. Novel well-tolerated therapeutic strategies as add-ons to statin therapy, or as monotherapy in cases of statin intolerance, are therefore essential in the management of $\mathrm{FH} \mathrm{[60].} \mathrm{In} \mathrm{patients} \mathrm{with} \mathrm{HeFH,} \mathrm{LDL-C}$ target levels are frequently not reached via statins alone because the baseline levels are very high. In patients with HoFH with no residual LDLR function, statins do not reduce LDL-C levels at all. In patients with $\mathrm{HoFH}$ with little residual LDLR activity, only modest reductions (10-25\%) in LDL-C serum concentrations are reached even at the highest doses of the most efficacious statins $[58,60]$. These patients depend on extracorporeal LDL elimination by apheresis.

\section{Prevention of Cardiovascular Events}

The 'LDL hypothesis' is a concept suggesting that it is the reduction of LDL-C, regardless of the means (i.e. not just via statins), that produces a corresponding reduction in cardiovascular events [65]. An alternative theory, the 'statin hypothesis', postulates that statins have unique efficacy in ASCVD that is not shared by other lipid-lowering agents and that LDL-C reduction is not the (only) basis for the beneficial effects of statins [65]. Notably, pleiotropic effects arising from the inhibition of 3-hydroxy3-methyl-glutaryl-CoA (HMG CoA) reductase, rather than from LDL-C lowering, have been made responsible: inhibition of $\mathrm{HMG} \mathrm{CoA}$ reductase not only limits the production of cholesterol, which is compensated by the upregulation of LDLRs and hence LDL uptake, but also the production of intermediary metabolites, which play important regulatory roles, for example by prenylation of many membrane proteins. This mechanism may explain muscle toxicity at high systemic exposure.

Recent data from IMPROVE-IT (Improved Reduction of Outcomes: Vytorin Efficacy International Trial) emphasize the importance of LDL-C lowering as the primary strategy to prevent CHD [65]. After 7 years of follow-up of 18,144 patients who had experienced an acute coronary syndrome, the rate of the primary endpoint (a composite of cardiovascular death, major coronary event [non-fatal myocardial infarction, unstable angina, or nonfatal stroke]) was $2 \%$ lower in the combination therapy group (simvastatin $40 \mathrm{mg}$ plus ezetimibe $10 \mathrm{mg}$ ) than in 
the simvastatin monotherapy group (33 vs. $35 \%$ ) [66]. One of the most important implications of this trial is that all reductions in LDL-C levels by enhanced hepatic LDL removal through the LDLR pathway are beneficial [65]. This is also suggested by the currently available outcome data on proprotein convertase subtilisin/kexin type 9 (PCSK9) inhibitors, which are discussed in section 6.2.

Further evidence in support of the causal role of LDL and LDL-C in the pathogenesis of ASCVD has been derived from Mendelian randomization (MR) studies. A particular advantage of the MR approach is that it can provide information on the impact of a lifetime modulation of a biomarker [67]. In this respect, MR studies demonstrated that frequent variants in the $L D L R$ gene, which increase LDL-C as early as in childhood by $15 \mathrm{mg} / \mathrm{dl}$, result in stronger effects on coronary artery disease risk than predicted by epidemiological or clinical studies for such a degree of LDL variability [68]. Conversely, individuals carrying a rare PCSK9 allele, which lowers LDL way below population average (by $21-38 \mathrm{mg} / \mathrm{dl}$ ), showed a marked 40-80\% reduced incidence of myocardial infarction [69].

\section{Alternative Treatment Options After Statin Use}

When the maximally tolerated dose of statin therapy fails to achieve the target LDL-C, clinicians need to consider alternative and/or add-on second- and third-line options. In these cases, combination therapy should be considered [70].

\subsection{Ezetimibe}

Ezetimibe is the first lipid-lowering agent that inhibits intestinal uptake of dietary and biliary cholesterol without affecting the absorption of fat-soluble nutrients [70]. The interrupted enterohepatic circulation and enhanced fecal loss of cholesterol is compensated by upregulation of LDLR and LDL uptake into the liver. Combining ezetimibe with a statin (simvastatin) in IMPROVE-IT reduced LDL-C by an additional $24 \%$ in stable patients who had experienced an acute coronary syndrome [66]. In addition, the statin-ezetimibe combination can decrease LDL-C by $60-70 \%$ in patients with FH [60]. In view of the acceptable side-effect profile and high compliance, the EAS recommends co-administration of ezetimibe as an add-on to statin therapy [60]. IMPROVE-IT [66], the first trial to demonstrate an incremental clinical benefit from adding a non-statin agent (ezetimibe) to statin therapy, found no significant differences in rates of adverse events between the combination therapy and monotherapy groups [65]. The
IMPROVE-IT findings are in line with data from an MR study that found that mutations in NPC1L1 are associated with reduced levels of LDL-C and reduced risk of ASCVD [71]. Together, the MR and trial data support the 'LDL hypothesis' regarding reduction of cardiovascular events in patients with cardiovascular risk factors.

\subsection{Proprotein Convertase Subtilisin/Kexin Type 9 (PCSK9) Inhibitors}

PCSK9 is a secreted protease that mediates LDLR degradation (Fig. 1a) [57, 59, 72, 73]. Its important contribution to the regulation of LDL-C levels was first demonstrated by the identification of gain-of-function mutations of the PCSK9 gene of patients with FH who had no mutations in the $L D L R$ or apolipoprotein-B (apoB) genes [69]. Additionally, individuals with loss-of-function mutations in PCSK9 were found to have reduced plasma levels of LDL$\mathrm{C}$ and to be protected from CHD [69, 74].

Inhibition of PCSK9 has emerged as a new therapeutic option. Three monoclonal antibodies are available: evolocumab, alirocumab, and bococizumab.

The complementary mechanisms of action of statins, PCSK9 and PCSK9 inhibitors are shown in Figs. 1 and 2. Statins inhibit cholesterol biosynthesis, leading to increased cellular sterol-regulatory element-binding protein-2 (SREBP-2) activity that promotes transcription of SREBP-2-inducible LDLR and PCSK9 genes (Fig. 2). However, this co-regulation is counteractive, as the production of PCSK9 protein triggers LDLR protein trafficking for lysosomal degradation and results in an attenuated LDL-C-lowering effect of statins [75]. The introduction of a PCSK9 inhibitor disrupts the interaction between PCSK9 and LDLR, raises LDLR protein, and increases LDL-C lowering as compared with statins alone (Fig. 1b).

Evolocumab, alirocumab, and bococizumab are currently being studied in large clinical trial programs and appear to be highly effective at reducing LDL-C levels, achieving an additional $60-75 \%$ reduction in patients treated with statins. Importantly, no significant increase in serious adverse events has been reported to date in phase III trials, in particular, no increase in myotoxicity when compared with statin-treated control patients [76].

In addition, small interfering RNAs-so-called antagomirs-have been developed to interfere with PCSK9 production in the liver. The previously published phase I trial is the first example of therapeutic RNA interference in humans [77].

Evolocumab PROFICIO Program PROFICIO (Programme to Reduce LDL-C and Cardiovascular Outcomes Following Inhibition of PCSK9 In Different Populations) is a large and comprehensive clinical trial program evaluating 


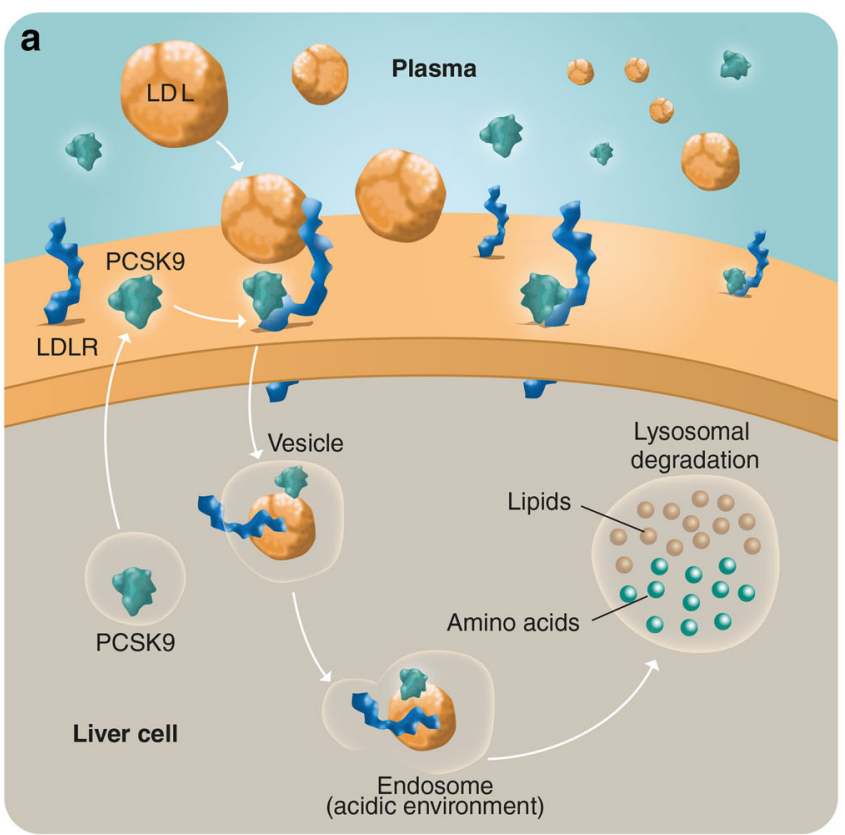

Fig. 1 Trafficking of LDLR in the presence of PCSK9 (a) or following PCSK9 inhibition by a monoclonal antibody (b). a Secreted PCSK9 binds to LDLR on the liver cell surface and mediates the lysosomal degradation of the complex formed by PCSK9, LDLR, and LDL [68]. $\mathbf{b}$ In the presence of a monoclonal antibody that binds to

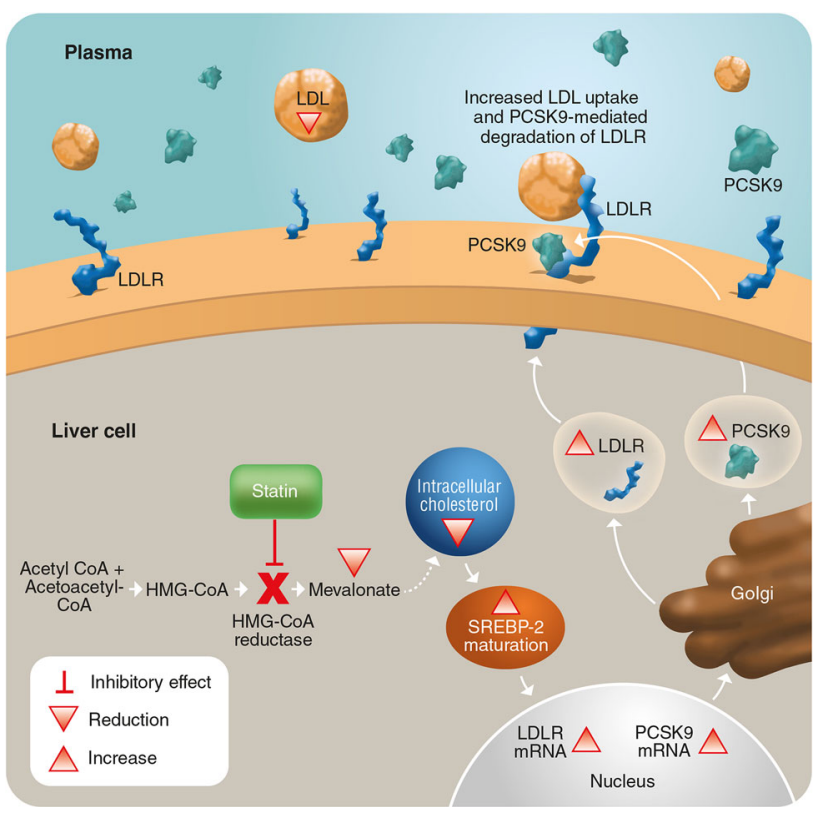

Fig. 2 Impact of statins on cholesterol metabolism. Statins inhibit the biosynthesis of intracellular cholesterol by inhibiting HMG-CoA reductase. This results in low levels of intracellular cholesterol, leading to increased SREBP-2 activity, which promotes the production of PCSK9 and LDLR, the degradation of which is mediated by PCSK9 [72]. HMG CoA 3-hydroxy-3-methyl-glutaryl-CoA, $L D L$ lowdensity lipoprotein, $L D L R$ low density lipoprotein receptor, $m R N A$ messenger RNA, PCSK9 proprotein convertase subtilisin/kexin type 9, SREBP-2 sterol-regulatory element-binding protein

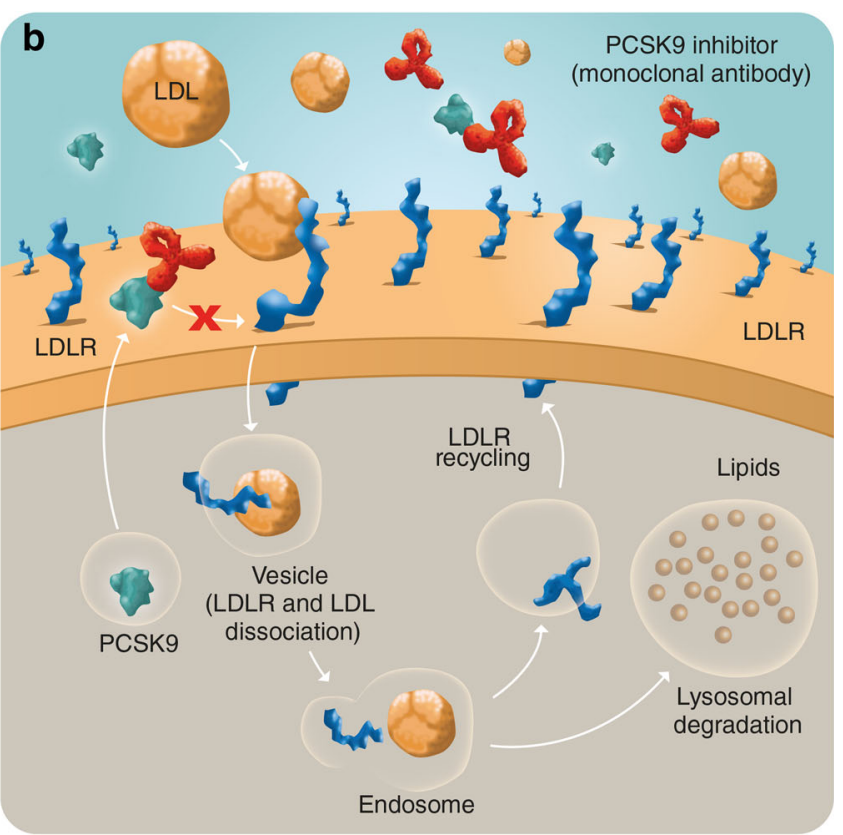

PCSK9, the PCSK9-mediated degradation of LDLR is inhibited, resulting in an increased uptake of LDL-cholesterol by LDLR as more LDLR are recycled at the cell surface [72]. $L D L$ low-density lipoprotein, LDLR low-density lipoprotein receptor, PCSK 9 proprotein convertase subtilisin/kexin type 9

evolocumab. The PROFICIO phase III program includes 14 trials, with a combined planned enrolment of more than 28,000 patients.

The phase III studies will evaluate subcutaneous evolocumab $140 \mathrm{mg}$ every 2 weeks and $420 \mathrm{mg}$ monthly in multiple patient populations, and four of the studies will provide long-term safety and additional efficacy or cardiovascular outcome data. Table 2 summarizes the currently available data from individual studies in patients with unmet needs. The evidence from trials in these patients indicates that evolocumab might be an efficacious and tolerable option for them, a conclusion also drawn by Dadu and Ballantyne [78] in their review of lipid lowering with PCSK9 inhibitors.

In addition, in a pooled analysis of four phase III studies (MENDEL-2, LAPLACE-2, RUTHERFORD-2, GAUSS2) that included 417 of 2729 patients with T2DM, the efficacy and safety of evolocumab was comparable in patients with or without T2DM and did not differ among T2DM sub-groups [85]. These findings were confirmed after 1 year of treatment in 4802 patients with, at high risk for, or at low risk for, diabetes mellitus who had completed one of 13 phase II or III parent studies of evolocumab (OSLER-1 and OSLER-2). Patients were randomized to receive either evolocumab $140 \mathrm{mg}$ every 2 weeks or $420 \mathrm{mg}$ monthly plus standard of care $(\mathrm{SoC})$ or $\mathrm{SoC}$ alone [86, 87]. Results were similar irrespective of parent-study 
Table 2 Summary of results from evolocumab trials in patient groups with unmet needs

\begin{tabular}{|c|c|c|c|c|}
\hline Study & Population & Primary endpoints & Efficacy & Safety \\
\hline $\begin{array}{l}\text { GAUSS-2 [79] } \\
\text { (evolocumab vs. } \\
\text { ezetimibe) }\end{array}$ & $\begin{array}{l}\text { Pts with hyperlipidemia } \\
\text { who cannot tolerate statin } \\
\text { therapy; } N=307\end{array}$ & $\begin{array}{l}\text { Percent change from } \\
\text { BL in LDL-C level } \\
\text { at the mean of } \\
\text { weeks } 10 \text { and } 12 \text {, } \\
\text { and at week } 12\end{array}$ & $\begin{array}{l}\text { Evolocumab reduced LDL-C } \\
\text { from BL by } 53-56 \% \text { : tx } \\
\text { differences vs. ezetimibe of } \\
37-39 \%(p<0.001)\end{array}$ & $\begin{array}{l}\text { Muscle AEs: } 12 \% \text { of } \\
\text { evolocumab-treated pts vs. } \\
23 \% \text { of ezetimibe-treated } \\
\text { pts; TEAEs and laboratory } \\
\text { abnormalities comparable } \\
\text { across tx groups }\end{array}$ \\
\hline $\begin{array}{l}\text { RUTHERFORD-2 } \\
\text { [80] (evolocumab vs. } \\
\text { PL) }\end{array}$ & $\begin{array}{l}\text { Pts with } \mathrm{HeFH} \text {, on } \\
\text { stable lipid-lowering } \\
\text { therapy; } N=329\end{array}$ & $\begin{array}{l}\text { Percent change from } \\
\text { BL in LDL-C level } \\
\text { at the mean of } \\
\text { weeks } 10 \text { and } 12 \text {, } \\
\text { and at week } 12\end{array}$ & $\begin{array}{l}\text { Evolocumab reduced mean } \\
\text { LDL-C at week } 12 \text { (every-2- } \\
\text { week dose: } 59 \% \text { reduction, } \\
\text { monthly dose: } 61 \% \\
\text { reduction; both } p<0.0001) \\
\text { and at the mean of week } 10 \\
\text { and } 12(60 \% \text { reduction and } \\
66 \% \text { reduction; both } \\
p<0.0001)\end{array}$ & $\begin{array}{l}\text { Similar rates of AEs in both } \\
\text { groups, except for } \\
\text { nasopharyngitis (19 pts [9\%] } \\
\text { in the evolocumab group vs. } \\
5 \text { [5\%] in the PL group) and } \\
\text { muscle-related AEs ( } 10 \text { pts } \\
\text { [5\%] in the evolocumab } \\
\text { group vs. } 1 \text { [1\%] in the PL } \\
\text { group) }\end{array}$ \\
\hline $\begin{array}{l}\text { TESLA [81] } \\
\text { (evolocumab vs. PL) }\end{array}$ & $\begin{array}{l}\text { Pts with } \mathrm{HoFH} \text {, on } \\
\text { stable lipid-lowering } \\
\text { therapy; } N=49\end{array}$ & $\begin{array}{l}\text { Percentage change } \\
\text { from BL in } \\
\text { ultracentrifugation } \\
\text { LDL-C level at } \\
\text { week } 12\end{array}$ & $\begin{array}{l}\text { Evolocumab reduced } \\
\text { ultracentrifugation LDL-C at } \\
12 \text { weeks by } 31 \% \\
(p<0.0001)\end{array}$ & $\begin{array}{l}\text { TEAEs occurred in } 10(63 \%) \\
\text { of } 16 \text { pts in the PL group and } \\
12(36 \%) \text { of } 33 \text { in the } \\
\text { evolocumab group }\end{array}$ \\
\hline $\begin{array}{l}\text { DESCARTES [82] } \\
\text { (evolocumab vs. PL) }\end{array}$ & $\begin{array}{l}\text { Pts with hyperlipidemia } \\
\text { and a wide range of } \mathrm{CV} \\
\text { risk, after a run-in period } \\
\text { of background lipid- } \\
\text { lowering therapy; } \\
N=901\end{array}$ & $\begin{array}{l}\text { Percent change from } \\
\text { BL in } \\
\text { ultracentrifugation } \\
\text { LDL-C level at } \\
\text { week } 52\end{array}$ & $\begin{array}{l}\text { Overall LSM }( \pm \mathrm{SE}) \text { reduction } \\
\text { in LDL-C } 57 \pm 2 \% \text { (taking } \\
\text { into account reduction in PL } \\
\text { group) }(p<0.001) \text {; mean } \\
\text { reduction } 56 \pm 4 \% \text { in pts } \\
\text { with diet alone as background } \\
\text { therapy, } 62 \pm 3 \% \text { with } \\
\text { atorvastatin } 10 \mathrm{mg}, \\
57 \pm 5 \% \text { with atorvastatin } \\
80 \mathrm{mg} \text {, and } 49 \pm 5 \% \text { with } \\
\text { combination of atorvastatin } \\
80 \mathrm{mg} \text { and ezetimibe } 10 \mathrm{mg} \\
\text { ( } p<0.001 \text { for all } \\
\text { comparisons) }\end{array}$ & $\begin{array}{l}\text { Overall incidence of AE } \\
\text { occurring during tx was } \\
\text { similar in the evolocumab } \\
\text { and PL groups: } 448 \text { of } 599 \\
\text { pts }(75 \%) \text { vs. } 224 \text { of } 302 \text { pts } \\
\text { ( } 74 \%) \text {; most common AEs } \\
\text { in the evolocumab group: } \\
\text { nasopharyngitis, URTI, } \\
\text { influenza, and back pain }\end{array}$ \\
\hline $\begin{array}{l}\text { LAPLACE-2 [83] } \\
\text { (evolocumab vs. } \\
\text { ezetimibe and PL) }\end{array}$ & $\begin{array}{l}\text { Pts at risk for CVD } \\
\text { receiving statin therapy; } \\
N=1899\end{array}$ & $\begin{array}{l}\text { Percent change from } \\
\text { BL in LDL-C level } \\
\text { at mean of weeks } \\
10 \text { and } 12 \text { and at } \\
\text { week } 12\end{array}$ & $\begin{array}{l}\text { Evolocumab reduced LDL-C } \\
\text { levels by } 66-75 \% \text { (every } \\
2 \text { weeks) and by } 63-75 \% \\
\text { (monthly) vs. PL at mean of } \\
\text { weeks } 10 \text { and } 12 \text { in the } \\
\text { moderate- and high-intensity } \\
\text { statin-treated groups; LDL-C } \\
\text { reductions at week } 12 \text { were } \\
\text { comparable }\end{array}$ & $\begin{array}{l}\text { AEs reported in } 36 \%, 40 \%, \\
\text { and } 39 \% \text { of evolocumab-, } \\
\text { ezetimibe-, and PL-treated } \\
\text { pts, respectively; most } \\
\text { common AEs in evolocumab- } \\
\text { treated pts were back pain, } \\
\text { arthralgia, headache, muscle } \\
\text { spasms, and pain in extremity } \\
(\text { all }<2 \%)\end{array}$ \\
\hline $\begin{array}{l}\text { TAUSSIG [84] } \\
\text { (evolocumab long- } \\
\text { term open-label; } \\
\text { interim results; } \\
\text { estimated } \\
\text { completion, January } \\
2020 \text { ) }\end{array}$ & $\begin{array}{l}\text { Pts with } \mathrm{HoFH} \text {, receiving } \\
\text { stable lipid-lowering } \\
\text { therapy; } N=100 \text { (non- } \\
\text { apheresis, } N=66 \text {; } \\
\text { apheresis, } N=34 \text { ) }\end{array}$ & $\begin{array}{l}\text { Percentage change } \\
\text { from BL in LDL-C } \\
\text { at week } 12\end{array}$ & $\begin{array}{l}\text { Evolocumab reduced LDL-C } \\
\text { in the overall cohort by } 21 \% \\
(p<0.05) \text {; reduction } \\
\text { maintained in the longer-term } \\
\text { (up to } 48 \text { weeks); in a subset } \\
\text { of non-apheresis pts, who } \\
\text { uptitrated to } 420 \mathrm{mg} \text { every } \\
2 \text { weeks }(N=28), \text { LDL-C } \\
\text { was reduced by a further } 6 \% \\
(p=0.01)\end{array}$ & $\begin{array}{l}\text { Evolocumab was well- } \\
\text { tolerated }\end{array}$ \\
\hline
\end{tabular}

$A E$ adverse effect, $B L$ baseline, $C V$ cardiovascular, $C V D$ cardiovascular disease, $H e F H$ heterozygous familial hypercholesterolaemia, $H o F H$ homozygous familial hypercholesterolaemia, $L D L-C$ low-density lipoprotein cholesterol, $L S M$ least squares mean, $P L$ placebo, $p t(s)$ patient(s), $S E$ standard error, TEAE treatment-emergent adverse effect, $t x$ treatment, URTI upper respiratory tract infection 
drug assignment. Evolocumab showed encouraging safety, with no measurable effect on skeletal muscle and glycemic parameters despite reducing LDL-C levels markedly.

Alirocumab ODYSSEY Program The ODYSSEY phase III program is expected to enroll more than 23,000 patients and currently includes 12 clinical trials of alirocumab, both in combination with other lipid-lowering agents and as monotherapy in patients with primary $\mathrm{HeFH}$ or non-FH or statin intolerance. Table 3 summarizes the currently available data from individual studies in patients with unmet needs. Similar to evolocumab, alirocumab appears to be effective in lowering LDL-C and well-tolerated.

In a sub-analysis of 2341 patients with or without T2DM from the ODYSSEY LONG TERM trial, the effects of alirocumab were also shown to be consistent, regardless of medical history of patients with T2DM at baseline [98]

Bococizumab SPIRE Program The bococizumab SPIRE program is currently underway in phase III trials. Table 4 describes these, although no results are yet available.

PCSK9 inhibitors For statin-intolerant patients specifically, promising results of the efficacy of PCSK9 inhibitors have already been shown in GAUSS 2 (Goal Achievement After Utilizing an Anti-PCSK9 Antibody in Statin Intolerant Subjects-2) (evolocumab vs. ezetimibe) (see Table 2); ODYSSEY ALTERNATIVE (alirocumab vs. ezetimibe) (see Table 3). The ongoing GAUSS-3 trial is the most recent statin intolerance study that incorporates a double-blind, placebo-controlled statin rechallenge prior to a 6-month evolocumab versus ezetimibe comparison, with a 2-year open-label extension. Further evidence will come from outcome trials; for now, LDL-C is an accepted marker for lipid-lowering therapies, and these data should be used for future guideline updates [104].

In conclusion, the available data on efficacy and safety of both evolocumab and alirocumab look very encouraging. Firm evidence will be obtained by clinical outcome trials that will be concluded in the near future $[105,106]$.

In 2015, evolocumab and alirocumab have received marketing authorization in the EU and the USA (Table 5). Despite their broad indications, the cost of monoclonal antibodies may restrict the use of PCSK9 inhibitors to patients with high LDL-C, where statins are not efficient enough, and to patients intolerant to statins, for whom these new treatment options may be the most cost effective $[76,107]$. The substantial potential health benefits and savings in healthcare costs from preventing CHD events will need to be weighed against the possibility of adverse effects of long-term statin therapy and the costs of alternative treatments.

\subsection{Other Statin Alternatives}

Novel potent LDL-C-lowering therapies currently under investigation include mipomersen, an apoB synthesis inhibitor [110-115], and lomitapide, a microsomal triglyceride transfer protein (MTP) inhibitor [116-119]. Unlike statins or PCSK9 inhibitors, which ultimately lower LDL-C by increasing LDLR expression in the liver and hence hepatic clearance of LDL-C, mipomersen and lomitapide inhibit the production of chylomicrons, very low-density lipoprotein (VLDL), and LDL. Independence of the LDLR makes these two regimens particularly applicable for the treatment of HoFH. However, the prevention of VLDL production increases hepatic fat accumulation. Consequently, mipomersen (only in the USA) and lomitapide (in the USA and Europe) are currently authorized for treatment of HoFH only.

Cholesteryl ester transfer protein (CETP) transfers cholesterol esters from HDL to LDL. Patients with CETP deficiency have high levels of HDL-C and low levels of LDL-C. CETP inhibitors have been developed, five of which have been or currently are in different stages of clinical investigation [120]. Whereas dalcetrapib only increased HDL-C levels, torcetrapib (ILLUMINATE trial) [121], anacetrapib (DEFINE trial) [122], evacetrapib [123], and TA-8995 (TULIP trial) [124] also caused 14-45\% decreases in LDL-C. However, clinical endpoint trials on torcetrapib, dalcetrapib, and evacetrapib have been stopped prematurely because of excess rates of serious adverse events (torcetrapib) or futility (dalcetrapib, evacetrapib). The anacetrapib phase III trial was very recently announced to be continued.

Other therapies, such as bile acid sequestrants and nicotinic acid, have been evaluated but found to be poorly tolerated [79]. Furthermore, the addition of niacin to statins did not further decrease major adverse cardiac event rates in the AIM-HIGH trial [125]. Consequently, niacin is no longer available in Europe.

\section{Controversies About Sub-Normally Low LDL-C Levels}

The beginning of cholesterol-lowering therapy in the 1980s witnessed a fierce discussion on the harm of low cholesterol.

Cholesterol is a natural component of the body's metabolism: together with other lipids, it is an essential constituent of cell membranes and a constituent of steroid hormones, vitamin D, and bile acids [126]. Cholesterol is also an indispensable component of cell membranes in the 


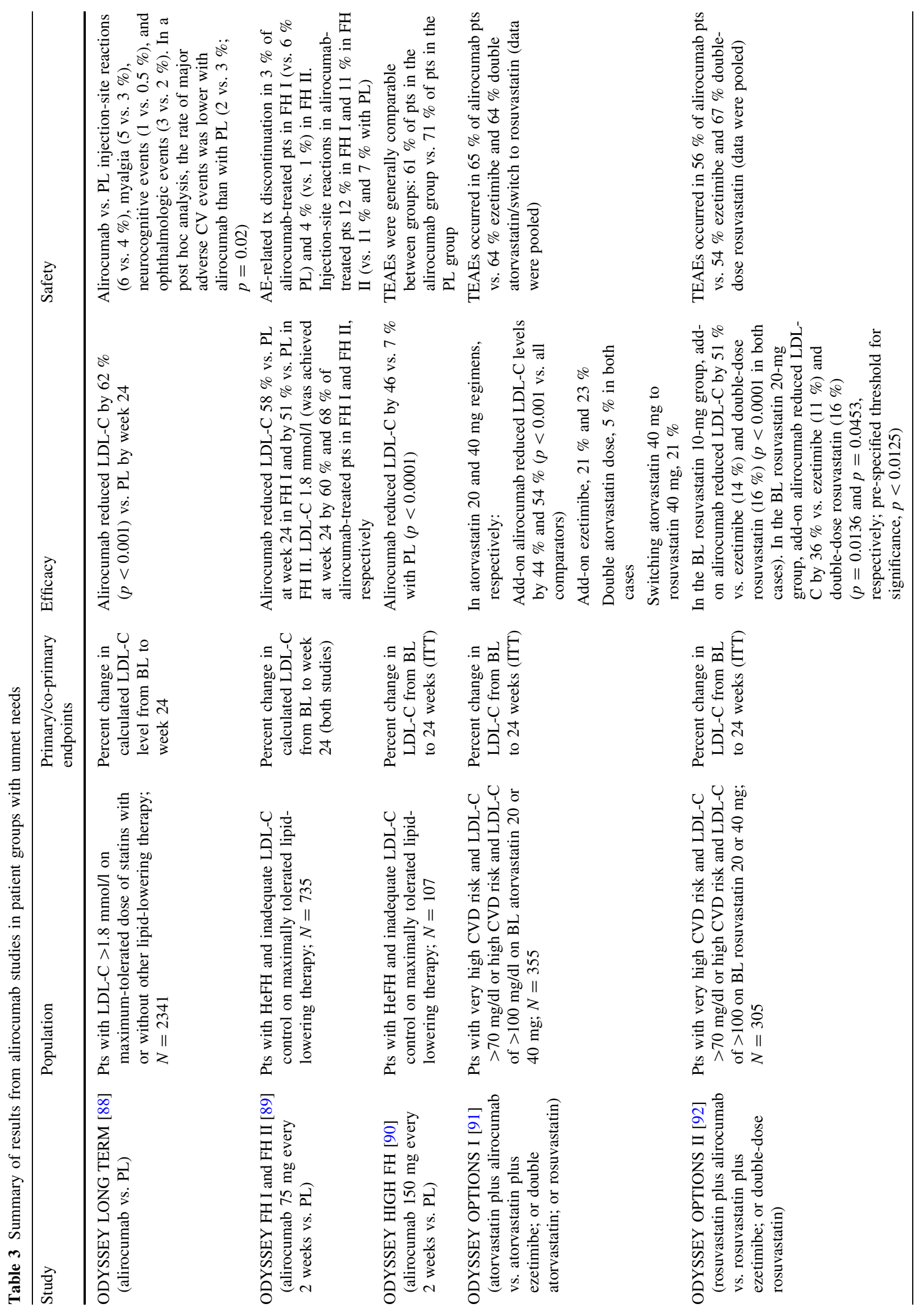




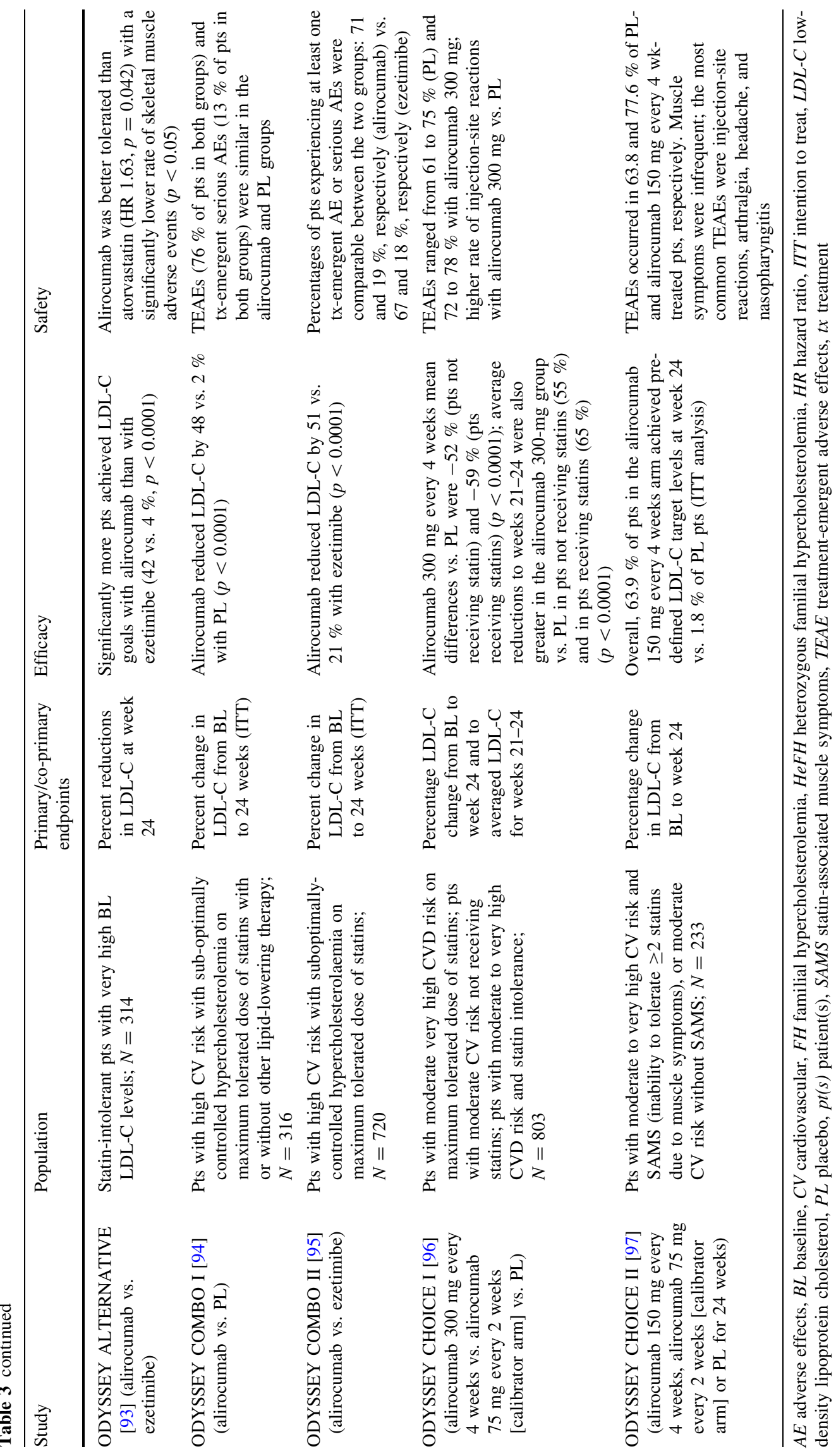


Table 4 Phase III bococizumab trials (ongoing)

\begin{tabular}{|c|c|c|c|}
\hline Study & Population & Comparison & $\begin{array}{l}\text { Estimated } \\
\text { completion }\end{array}$ \\
\hline $\begin{array}{l}\text { SPIRE-HF [99] https://clinicaltrials.gov/ } \\
\text { ct2/show/NCT01968980 }\end{array}$ & $\begin{array}{l}\text { Pts with } \mathrm{HeFH} \text { with high and very high CVD } \\
\text { risk (with statin therapy) }\end{array}$ & Bococizumab vs. PL at 12 weeks & January 2016 \\
\hline $\begin{array}{l}\text { SPIRE-HR [100] https://clinicaltrials.gov/ } \\
\text { ct2/show/NCT01968954 }\end{array}$ & $\begin{array}{l}\text { Pts with high and very high CVD risk (with } \\
\text { statin therapy) }\end{array}$ & Bococizumab vs. PL at 12 weeks & January 2016 \\
\hline $\begin{array}{l}\text { SPIRE-LDL [101] https://clinicaltrials. } \\
\text { gov/ct2/show/NCT01968967 }\end{array}$ & $\begin{array}{l}\text { Pts with high and very high CVD risk (with } \\
\text { statin therapy) }\end{array}$ & Bococizumab vs. PL at 12 weeks & $\begin{array}{l}\text { December } \\
2015\end{array}$ \\
\hline $\begin{array}{l}\text { SPIRE-1 [102] https://clinicaltrials.gov/ } \\
\text { ct2/show/NCT01975376 }\end{array}$ & $\begin{array}{l}\text { Pts with high and very high CVD risk (with } \\
\text { lipid-lowering therapy) }\end{array}$ & $\begin{array}{l}\text { Bococizumab vs. PL at } 5 \text { years } \\
\text { (effects on major CV events) }\end{array}$ & August 2017 \\
\hline $\begin{array}{l}\text { SPIRE-2 [103] https://clinicaltrials.gov/ } \\
\text { ct2/show/NCT01975389 }\end{array}$ & $\begin{array}{l}\text { Pts with high and very high CVD risk (with } \\
\text { lipid-lowering therapy) }\end{array}$ & $\begin{array}{l}\text { Bococizumab vs. PL at } 5 \text { years } \\
\text { (effects on major CV events) }\end{array}$ & August 2017 \\
\hline
\end{tabular}

$C V$ cardiovascular, $C V D$ cardiovascular disease, $\mathrm{HeFH}$ heterozygous familial hypercholesterolemia, $P L$ placebo

Table 5 PCSK9 inhibitors approved in Europe and the USA

\begin{tabular}{|c|c|}
\hline PCSK9 inhibitor & Indications \\
\hline $\begin{array}{l}\text { Evolocumab [108] } \\
\text { (evolocumab SmPC) }\end{array}$ & $\begin{array}{l}\text { Adults with primary hypercholesterolemia (heterozygous familial and non-familial) or mixed dyslipidemia, as } \\
\text { an adjunct to diet in combination with a statin or statin with other lipid-lowering therapies in pts unable to } \\
\text { reach LDL-C goals with the maximum tolerated dose of a statin or alone or in combination with other lipid- } \\
\text { lowering therapies in pts who are statin intolerant or for whom a statin is contraindicated } \\
\text { Adults and adolescents aged } \geq 12 \text { years with homozygous FH in combination with other lipid-lowering } \\
\text { therapies }\end{array}$ \\
\hline $\begin{array}{l}\text { Alirocumab [109] (alirocumab } \\
\text { SmPC) }\end{array}$ & $\begin{array}{l}\text { Adults with primary hypercholesterolaemia (heterozygous familial and non-familial) or mixed dyslipidemia as } \\
\text { an adjunct to diet: in combination with a statin or statin with other lipid-lowering therapies in pts unable to } \\
\text { reach LDL-C goals with the maximum tolerated dose of a statin or alone or in combination with other lipid- } \\
\text { lowering therapies in pts who are statin intolerant or for whom a statin is contraindicated }\end{array}$ \\
\hline
\end{tabular}

FH familial hypercholesterolemia, $L D L-C$ low-density lipoprotein cholesterol, $p t(s)$ patient(s), $S m P C$ summary of product characteristics

brain [126]. Interestingly, there have been reports of higher all-cause mortality in populations with sub-normally low cholesterol levels [126]. For example, MRFIT (Multiple Risk Factor Intervention Trial) and other older studies suggested increased mortality of malignant and other disorders in individuals with serum cholesterol $<3.6 \mathrm{mmol} / 1$ $(140 \mathrm{mg} / \mathrm{dl})$ [126, 127]. However, this association may result from reverse causality: individuals with low cholesterol may have pre-clinical severe diseases that decrease cholesterol levels. After adjustment for body weight and smoking, the J-shaped relationship between cholesterol and total mortality disappeared. Moreover, 25 years of trial experience with statins do not indicate any increase in risk for serious life-threatening or life expectancy-limiting disease [126].

Nevertheless, the advent of very effective combination therapies for LDL-C lowering will revive the discussion on the potential threats from very low cholesterol levels. Innate errors of metabolism may give some information in this regard. Many carriers of loss-of-function mutations in PCSK9 or angiopoietin-like protein type 4 (ANGPTL4), as well as carriers of mutations preventing the synthesis of full-length apoB, have very low levels of LDL-C. These conditions are not known to limit the life expectancy or quality of life of their carriers. Quite the opposite, they appear to dramatically reduce the risk of myocardial infarction [128, 129]. Only patients with homozygous hypobetalipoproteinemia and patients with abetalipoproteinemia (because of mutations in MTP) with complete absence of apoB-containing lipoproteins experience severe neurological disease such as ataxia and retinitis pigmentosa [130].

The adverse effects of extreme LDL-C lowering can be subclinical and overlooked for a long time. Thus, the increased risk of diabetes with statin treatment has been uncovered only recently, after 20 years of prior statin use. Initial data also point to increased loss of bone mass with statin treatment. However, the mechanism and hence extrapolation of the finding to non-statin interferences and LDL-C lowering in general is controversial. Some authors suggested that statins affect insulin secretion in beta cells as well as insulin signaling in peripheral target organs by interfering with the synthesis of bioactive intermediates in the mevalonate-cholesterol pathway $[131,132]$. In this 
case, non-statin mediated LDL-C lowering may not be diabetogenic. Others showed that LDL interferes with insulin secretion in an LDLR-dependent manner $[133,134]$, and that patients with FH are at reduced risk of diabetes [135]. In that case, non-statin interventions that upregulate the LDLR in pancreatic beta cells may also be diabetogenic.

However, follow-up of whether these changes in intermediary phenotypes lead to adverse clinical outcomes will be required. With respect to diabetes, it is important to highlight that statins reduce coronary event rates as well as the incidence of diabetic nephropathy.

Nonetheless, these examples indicate an urgent need to closely monitor the efficacy and safety of novel cholesterol-lowering regimens, such as PCSK9 inhibitors. For safety, it will be important to use methods that objectively measure specific endpoints, such as cognitive and other brain functions.

\section{Conclusions}

Statins are currently the SoC in the management of dyslipidemia. Treatment guidelines recommend optimization of statin dose when patients do not reach LDL-C targets. However, treatment aims may not be reached with statins in many patients at high risk of cardiovascular events, such as patients with $\mathrm{FH}$ or statin intolerance. Such patients require more effective treatment options and may benefit from combination therapy with ezetimibe or a PCSK9 inhibitor. PCSK9 inhibitors are now available, and treatment guidelines need to be updated to guide the management of patients who will best benefit from these new treatments.

Acknowledgments The authors would like to thank Diane Rees of Zenith Healthcare Communications Ltd who provided medical writing support, which was funded by Amgen (Europe) GmbH. Editorial support was provided by Carine Thual of Amgen (Europe) $\mathrm{GmbH}$.

\section{Compliance with ethical standards}

Conflict of interest Stephan Krähenbühl is the local principal investigator of a clinical study sponsored by Amgen and has given talks about the pharmacology and safety of PCSK9 inhibitors in scientific meetings sponsored by Amgen and Sanofi. Arnold von Eckardstein received honoraria from Amgen, Sanofi-Aventis, and Merck Sharpe and Dohme for lectures or consultancies. Ivana PavikMezzour is an employee of Amgen and owns stocks.

Open Access This article is distributed under the terms of the Creative Commons Attribution-NonCommercial 4.0 International License (http://creativecommons.org/licenses/by-nc/4.0/), which permits any noncommercial use, distribution, and reproduction in any medium, provided you give appropriate credit to the original author(s) and the source, provide a link to the Creative Commons license, and indicate if changes were made.

\section{References}

1. European Cardiovascular Disease Statistics 2012 edition. http:// www.escardio.org/The-ESC/Initiatives/EuroHeart/2012-EuropeanCardiovascular-Disease-Statistics. Last accessed Jan 2016.

2. Reiner Z, Catapano AL, De Backer G, et al. ESC/EAS Guidelines for the management of dyslipidemias: the Task Force for the management of dyslipidemias of the European Society of Cardiology (ESC) and the European Atherosclerosis Society (EAS). Eur Heart J. 2011;32:1769-818.

3. Cholesterol Treatment Trialists' (CTT) Collaboration. Efficacy and safety of more intensive lowering of LDL cholesterol: a meta-analysis of data from 170000 participants in 26 randomised trials. Lancet. 2010;376:1670-81.

4. Cholesterol Treatment Trialists' (CTT) Collaboration. The effects of lowering LDL cholesterol with statin therapy in people at low risk of vascular disease: meta-analysis of individual data from 27 randomised trials. Lancet. 2012;380:581-90.

5. Cholesterol Treatment Trialists' (CTT) Collaboration. Efficacy and safety of LDL-lowering therapy among men and women: meta-analysis of individual data from 174,000 participants in 27 randomised trials. Lancet. 2015;385:1397-405.

6. Brugts JJ, Yetgin T, Hoeks SE, et al. The benefits of statins in people without established cardiovascular disease but with cardiovascular risk factors: meta-analysis of randomised controlled trials. BMJ. 2009;338:b2376.

7. Mills EJ, Rachlis B, Wu P, et al. Primary prevention of cardiovascular mortality and events with statin treatments. A network meta-analysis involving more than 65,000 patients. J Am Coll Cardiol. 2008;52:1769-81.

8. Shalev V, Chodick G, Silber H, et al. Continuation of statin treatment and all-cause mortality: a population-based cohort study. Arch Intern Med. 2009;169:260-8.

9. Taylor F, Huffman MD, Macedo AF, et al. Statins for the primary prevention of cardiovascular disease. Cochrane Database Syst Rev. 2013;1:CD004816.

10. Chodick G, Shalev V, Gerber Y, et al. Long-term persistence with statin treatment in a not-for-profit health maintenance organization: a population-based retrospective cohort study in Israel. Clin Ther. 2008;30:2167-79.

11. Cooney MT, Dudina AL, Graham IM. Value and limitations of existing scores for the assessment of cardiovascular risk. A review for clinicians. J Am Coll Cardiol. 2009;54:1209-27.

12. Cooney MT, Dudina A, d'Agostino R, Graham IM. Cardiovascular risk estimation systems in primary prevention Do they differ? Do they make a difference? Can we see the future? Circulation. 2010;122:300-10.

13. Goff DC Jr, Lloyd-Jones DM, Bennett G, et al. 2013 ACC/AHA guideline on the assessment of cardiovascular risk. A report of the American College of Cardiology/American Heart Association Task Force on practice guidelines. Circulation. 2014;129:S49-73.

14. Conroy R, Pyorala K, Fitzgerald AP, et al. Estimation of tenyear risk of fatal cardiovascular disease in Europe: the SCORE project. Eur Heart J. 2003;24:987-1003.

15. D'Agostino RB Sr, Vasan RS, Pencina MJ, et al. General cardiovascular risk profile for use in primary care: the Framingham Heart Study. Circulation. 2008;117:743-53.

16. Kavousi M, Leening MJ, Nanchen D, et al. Comparison of application of the ACC/AHA guidelines, Adult Treatment Panel III guidelines, and European Society of Cardiology guidelines for cardiovascular disease prevention in a European cohort. JAMA. 2014;311:1416-23. 
17. Colantonio LD, Baber U, Banach M, et al. Contrasting cholesterol management guidelines for adults with CKD. J Am Soc Nephrol. 2015;26:1173-80.

18. Thompson PD, Clarkson P, Karas RH. Statin-associated myopathy. JAMA. 2003;289:1681-90.

19. Rasmussen JN, Chong A, Alter DA. Relationship between adherence to evidence-based pharmacotherapy and long-term mortality after acute myocardial infarction. JAMA. 2007;297:177-86.

20. Bouchard MH, Dragomir A, Blais L, et al. Impact of adherence to statins on coronary artery disease in primary prevention. $\mathrm{Br} \mathrm{J}$ Clin Pharmacol. 2007;3:3.

21. Ho PM, Spertus JA, Masoudi FA, et al. Impact of medication therapy discontinuation on mortality after myocardial infarction. Arch Intern Med. 2006;166:1842-7.

22. Avorn J, Monette J, Lacour A, et al. Persistence of use of lipidlowering medications: a cross-national study. JAMA. 1998;279:1458-62.

23. Benner JS, Glynn RJ, Mogun H, et al. Long-term persistence in use of statin therapy in elderly patients. JAMA. 2002;288:455-61.

24. Mann DM, Woodard M, Muntner P, et al. Predictors of nonadherence to statins: a systematic review and meta-analysis. Ann Pharmacother. 2010;44:1410-21.

25. Zeller A, Taegtmeyer A, Martina B, et al. Physicians' ability to predict patients' adherence to antihypertensive medication in primary care. Hypertens Res. 2008;31:1765-71.

26. Fung V, Sinclair F, Wang H, et al. Patients' perspectives on nonadherence to statin therapy: a focus-group study. Perm J. 2010;14:4-10

27. Casula M, Tragni E, Catapano AL. Adherence to lipid-lowering treatment: the patient perspective. Patient Prefer Adherence. 2012;6:805-14.

28. Banach M, Rizzo M, Toth PP, et al. Statin intolerance-an attempt at a unified definition. Position paper from an International Lipid Expert Panel. Arch Med Sci. 2015;11:1-23.

29. Shah RV, Goldfine AB. Statins and risk of new-onset diabetes mellitus. Circulation. 2012;126:e282-4.

30. Skoumas J, Liontou C, Chrysohoou C, et al. Statin therapy and risk of diabetes in patients with heterozygous familial hypercholesterolemia or familial combined hyperlipidemia. Atherosclerosis. 2014;237:140-5.

31. Maki KC, Ridker PM, Brown WV, The Diabetes Subpanel of the National Lipid Association Expert Panel, et al. An assessment by the Statin Diabetes Safety Task Force: 2014 update. J Clin Lipidol. 2014;8:S17-29.

32. Thapa R, Sharma S, Jeevanantham V, et al. Disparities in lipid control and statin drug use among diabetics with noncoronary atherosclerotic vascular disease versus those with coronary artery disease. J Clin Lipidol. 2015;9:241-6.

33. Spinler SA, Cziraky MJ, Willey VJ, et al. Frequency of attainment of low-density lipoprotein cholesterol and non-high-density lipoprotein cholesterol goals in cardiovascular clinical practice (from the National Cardiovascular Data Registry PINNACLE Registry). Am J Cardiol. 2015;116:547-53.

34. Stroes ES, Thompson PD, Corsini A, European Atherosclerosis Society Consensus Panel, et al. Statin-associated muscle symptoms: impact on statin therapy-European Atherosclerosis Society Consensus Panel statement on assessment, aetiology and management. Eur Heart J. 2015;1(36):1012-22.

35. Rosenson RS, Baker SK, Jacobson TA, et al. An assessment by the statin muscle safety task force: 2014 update. J Clin Lipidol. 2014;8:S58-71.

36. Reiner Z. Resistance and intolerance to statins. Nutr Metab Cardiovasc Dis. 2014;24:1057-66.
37. Mancini GB, Tashakkor AY, Baker S, et al. Diagnosis, prevention, and management of statin adverse effects and intolerance: Canadian Working Group Consensus update. Can J Cardiol. 2013;29:1553-68.

38. Jacobson TA. Toward "pain-free" statin prescribing: clinical algorithm for diagnosis and management of myalgia. Mayo Clin Proc. 2008;83:687-700.

39. Cho L. Management of statin intolerant high risk patient: what are the current options. Presentation at the annual meeting of the European Society of Cardiology; 29 August-02 September 2015, London, UK.

40. Bruckert E, Hayem G, Dejager S, et al. Mild to moderate muscular symptoms with high-dosage statin therapy in hyperlipidemic patients - the PRIMO study. Cardiovasc Drugs Ther. 2005;19:403-14

41. Nichols GA, Koro CE. Does statin therapy initiation increase the risk for myopathy? An observational study of 32,225 diabetic and nondiabetic patients. Clin Ther. 2007;29:1761-70.

42. Buettner C, Rippberger MJ, Smith JK, et al. Statin use and musculoskeletal pain among adults with and without arthritis. Am J Med. 2012;125:176-82.

43. Cohen JD, Brinton EA, Ito MK, Jacobson TA. Understanding statin use in America and gaps in patient education (USAGE): an internet-based survey of 10,138 current and former statin users. J Clin Lipidol. 2012;6:208-15.

44. Zhang H, Plutzky J, Skentzos S, et al. Discontinuation of statins in routine care settings: a cohort study. Ann Int Med. 2013;158:526-34.

45. El-Salem K, Ababeneh B, Rudnicki S, et al. Prevalence and risk factors of muscle complications secondary to statins. Muscle Nerve. 2011;44:877-81.

46. Parker BA, Capizzi JA, Grimaldi AS, et al. Effect of statins on skeletal muscle function. Circulation. 2013;127:96-103.

47. Ballantyne CM, Corsini A, Davidson $\mathrm{MH}$, et al. Risk for myopathy with statin therapy in high-risk patients. Arch Intern Med. 2003;163:553-64.

48. Graham DJ, Staffa JA, Shatin D, et al. Incidence of hospitalized rhabdomyolysis in patients treated with lipid-lowering drugs. JAMA. 2004;292:2585-90.

49. Roten L, Schoenenberger RA, Krähenbühl S, Schlienger RG. Rhabdomyolysis in association with simvastatin and amiodarone. Ann Pharmacother. 2004;38:978-81.

50. Golomb BA, Evans MA. Statin adverse effects: a review of the literature and evidence for a mitochondrial mechanism. Am J Cardiovasc Drugs. 2008;8:373-418.

51. Silva M, Matthews ML, Jarvis C, et al. Meta-analysis of druginduced adverse events associated with intensive-dose statin therapy. Clin Ther. 2007;29:253-60.

52. Dale KM, Coleman CI, Henyan NN, et al. Does more aggressive statin therapy increase muscle and liver risk? 55th Annual Scientific Sessions of the American College of Cardiology. Atlanta, GA, March 11-14, 2006.

53. SEARCH Collaborative Group, Link E, Parish S. SLCO1B1 variants and statin-induced myopathy-a genomewide study. N Engl J Med. 2008;359:789-99.

54. Golomb B, Yang E, Denenberg J, et al. Statin-associated muscle adverse effects. Circulation. 2003;107:e7028-9.

55. Barkas F, Liberopoulos EN, Kostapanos MS, et al. Lipid target achievement among patients with very high and high cardiovascular risk in a lipid clinic. Angiology. 2015;66:346-53.

56. Rodriguez F, Olufade T, Heithoff K, et al. Frequency of highrisk patients not receiving high-potency statin (from a large managed care database). Am J Cardiol. 2015;115:190-5.

57. Vogt A. The genetics of familial hypercholesterolemia and emerging therapies. Appl Clin Genet. 2015;8:27-36. 
58. Cuchel M, Bruckert E, Ginsberg HN, European Atherosclerosis Society Consensus Panel on Familial Hypercholesterolemia, et al. Homozygous familial hypercholesterolemia: new insights and guidance for clinicians to improve detection and clinical management. A position paper from the Consensus Panel on Familial Hypercholesterolemia of the European Atherosclerosis Society. Eur Heart J. 2014;35:2146-57.

59. Ito MK, Watts GF. Challenges in the diagnosis and treatment of homozygous familial hypercholesterolemia. Drugs. 2015;75:1715-24.

60. Nordestgaard MJ, Chapman SE, Humphries HN, For the European Atherosclerosis Society Consensus, et al. Familial hypercholesterolemia is underdiagnosed and undertreated in the general population: guidance for clinicians to prevent coronary heart disease: consensus Statement of the European Atherosclerosis Society. Eur Heart J. 2013;34:3478-90.

61. Goldstein JK, Hobbs HH, Brown MS. Familial hypercholesterolemia. In: Scriver CR, Beaudet AL, Sly WS, Valle D, editors. The metabolic and molecular bases of inherited disease. 8th ed. New York: McGraw-Hill; 2001. p. 2863-913.

62. Sniderman AD, Tsimikas S, Fazio S. The severe hypercholesterolemia phenotype: clinical diagnosis, management, and emerging therapies. J Am Coll Cardiol. 2014;63:1935-47.

63. Vishwanath R, Hemphill LC. Familial hypercholesterolemia and estimation of US patients eligible for low-density lipoprotein apheresis after maximally tolerated lipid-lowering therapy. J Clin Lipidol. 2014;8:18-28.

64. Sjouke B, Kusters DM, Kindt I, et al. Homozygous autosomal dominant hypercholesterolemia in the Netherlands: prevalence, genotype-phenotype relationship, and clinical outcome. Eur Heart J. 2015;36:560-5.

65. Jarcho JA, Keaney JF Jr. Proof that lower is better-LDL cholesterol and IMPROVE-IT. N Engl J Med. 2015;372:2448-50.

66. Cannon CP, Blazing MA, Giugliano RP, et al. Ezetimibe added to statin therapy after acute coronary syndromes. N Engl J Med. 2015;372:2387-97.

67. Jansen H, Samani NJ, Schunkert H. Mendelian randomization studies in coronary artery disease. Eur Heart J. 2014;35:1917-24.

68. Linsel-Nitschke P, Gotz A, Erdmann J, et al. Lifelong reduction of LDL-cholesterol related to a common variant in the LDLreceptor gene decreases the risk of coronary artery disease-a Mendelian randomisation study. PLoS One. 2008;8:2986.

69. Cohen JC, Boerwinkle E, Mosley TH Jr, et al. Sequence variations in PCSK9, low LDL, and protection against coronary heart disease. N Engl J Med. 2006;354:1264-72.

70. Reiner Z. Combined therapy in the treatment of dyslipidemia. Fundam Clin Pharmacol. 2010;24:19-28.

71. Lauridsen BK, Stender S, Frikke-Schmidt R, et al. Genetic variation in the cholesterol transporter NPC1L1, ischaemic vascular disease, and gallstone disease. Eur Heart J. 2015;36:1601-8.

72. Horton JD, Cohen JC, Hobbs HH. PCSK9: a convertase that coordinates LDL catabolism. J Lipid Res. 2009;50(Suppl):S172-7.

73. Varret M, Rabes JP, Saint-Jore B, et al. A third major locus for autosomal dominant hypercholesterolemia maps to $1 \mathrm{p} 34.1-\mathrm{p} 32$. Am J Hum Genet. 1999;64:1378-87.

74. Cohen J, Pertsemlidis A, Kotowski IK, et al. Low LDL cholesterol in individuals of African descent resulting from frequent nonsense mutations in PCSK9. Nat Genet. 2005;37:161-5.

75. Zhang L, McCabe T, Condra JH, et al. An anti-PCSK9 antibody reduces LDL-cholesterol on top of a statin and suppresses hepatocyte SREBP-regulated genes. Int J Biol Sci. 2012;8(310-27):76.
76. Dorey E. Cholesterol-busting PCSK9 drugs. Pharm J. 2015. http:// www.pharmaceutical-journal.com/news-and-analysis/features/ pcsk9-inhibitors-the-next-cholesterol-lowering-blockbusters/200 68181.article. Last accessed Jan 2016.

77. Fitzgerald K, Frank-Kamenetsky M, Shulga-Morskaya S, et al. Effect of an RNA interference drug on the synthesis of proprotein convertase subtilisin/kexin type 9 (PCSK9) and the concentration of serum LDL cholesterol in healthy volunteers: a randomised, single-blind, placebo-controlled, phase 1 trial. Lancet. 2014;383:60-8.

78. Dadu RT, Ballantyne CM. Lipid lowering with PCSK9 inhibitors. Nat Rev Cardiol. 2014;11:563-75.

79. Stroes E, Colquhoun D, Sullivan D, et al. GAUSS-2 Investigators. Anti-PCSK9 antibody effectively lowers cholesterol in patients with statin intolerance: the GAUSS-2 randomized, placebo-controlled phase 3 clinical trial of evolocumab. J Am Coll Cardiol. 2014;63:2541-8.

80. Raal FJ, Stein EA, Dufour R, RUTHERFORD-2 Investigators, et al. PCSK9 inhibition with evolocumab (AMG 145) in heterozygous familial hypercholesterolaemia (RUTHERFORD2): a randomised, double-blind, placebo-controlled trial. Lancet. 2015;385:331-40.

81. Raal FJ, Honarpour N, Blom DJ, et al. Inhibition of PCSK9 with evolocumab in homozygous familial hypercholesterolaemia (TESLA Part B): a randomised, double-blind, placebo-controlled trial. Lancet. 2015;385:341-50.

82. Blom DJ, Djedjos CS, Monsalvo ML, et al. Effects of evolocumab on vitamin e and steroid hormone levels: results from the 52-week, phase 3, double-blind, randomized, placebo-controlled DESCARTES study. Circ Res. 2015;117:731-41.

83. Robinson JG, Rogers WJ, Nedergaard BS, et al. Rationale and design of LAPLACE-2: a phase 3, randomized, double-blind, placebo- and ezetimibe-controlled trial evaluating the efficacy and safety of evolocumab in subjects with hypercholesterolemia on background statin therapy. Clin Cardiol. 2014;37:195-203.

84. Raal F, Hovingh K, Santos R, et al. Long-term treatment with evolocumab in patients with homozygous familial hypercholesterolaemia $(\mathrm{HoFH})$ : interim results from the trial assessing long-term use of PCSK9 inhibition in subjects with genetic LDL disorder (TAUSSIG) study. Abstract no. 255 presented at 17th International Symposium on Atherosclerosis. 2015.

85. Sattar NA, Djedjos CS, Robinson JG, et al. Efficacy and safety of the PCSK9 inhibitor evolocumab (AMG 145) in patients with type 2 diabetes. Abstract no. 257 presented at the 75th Annual Scientific Sessions of the American Diabetes Association. 2015.

86. Preiss D. Oral presentation at EASD 2015. Should we worry about raised triglycerides: the controversy continues. http:// www.easdvirtualmeeting.org/resources/should-we-worry-aboutraised-triglycerides-the-controversy-continues. Last accessed Jan 2016.

87. Sattar N, Preiss D, Blom D, et al. Evaluation of the one-year efficacy, safety and glycaemic effects of evolocumab (AMG 145 ) in 4,802 subjects with, at high risk for, or at low risk for, diabetes mellitus. Abstract no. 157 presented at 51st Annual meeting of the European Association for the study of Diabetes. 2015.

88. Robinson JG, Farnier M, Krempf M, et al. ODYSSEY LONG TERM Investigators. Efficacy and safety of alirocumab in reducing lipids and cardiovascular events. $\mathrm{N}$ Engl $\mathrm{J}$ Med. 2015;372:1489-99.

89. Kastelein JJ, Ginsberg HN, Langslet G, et al. ODYSSEY FH I and FH II: 78 week results with alirocumab treatment in 735 patients with heterozygous familial hypercholesterolemia. Eur Heart J. 2015;36:2996-3003.

90. Ginsberg HN, Rader DJ, Raal FJ. ODYSSEY HIGH FH: efficacy and safety of alirocumab in patients with severe 
heterozygous familial hypercholesterolemia. Circulation. 2014;130:2119.

91. Bays H, Gaudet D, Weiss R, et al. Alirocumab as add-on to atorvastatin versus other lipid treatment strategies: ODYSSEY OPTIONS I randomized trial. J Clin Endocrinol Metab. 2015;100:3140-8.

92. Farnier M, Jones P, Severance R, et al. Efficacy and safety of adding alirocumab to rosuvastatin versus adding ezetimibe or doubling the rosuvastatin dose in high cardiovascular-risk patients: the ODYSSEY OPTIONS II randomized trial. Atherosclerosis. 2016;244:138-46.

93. Moriarty PM, Jacobson TA, Bruckert E, et al. Efficacy and safety of alirocumab, a monoclonal antibody to PCSK9, in statin-intolerant patients: design and rationale of ODYSSEY ALTERNATIVE, a randomized phase 3 trial. J Clin Lipidol. 2014;8:554-61.

94. Kereiakes DJ, Robinson JG, Cannon CP, et al. Efficacy and safety of the proprotein convertase subtilisin/kexin type 9 inhibitor alirocumab among high cardiovascular risk patients on maximally tolerated statin therapy: The ODYSSEY COMBO I study. Am Heart J. 2015;169(906-915):e13.

95. Cannon CP, Cariou B, Blom D, et al. Efficacy and safety of alirocumab in high cardiovascular risk patients with inadequately controlled hypercholesterolaemia on maximally tolerated doses of statins: the ODYSSEY COMBO II randomized controlled trial. Eur Heart J. 2015;36:1186-94.

96. Roth E, Rader DJ, Moriarty P. Phase 3 randomized trial evaluating alirocumab every four weeks dosing as add-on to statin or as monotherapy: ODYSSEY CHOICE I. Abstract no. 0254 presented at 17th International Symposium on Atherosclerosis. 2015 .

97. Stroes E, Guyton J, Farnier M. Alirocumab in patients with hypercholesterolemia not on statin therapy: the ODYSSEY CHOICE II study. Abstract no. 0269 presented at 17th International Symposium on Atherosclerosis. 2015.

98. Colhoun HM, Ginsberg HN, Leiter LA, et al. Efficacy and safety of alirocumab in individuals with diabetes: analyses from the ODYSSEY LONG TERM study. Abstract no. 158 presented at 51st Annual meeting of the European Association for the study of Diabetes. 2015.

99. A 52 week study to assess the use of bococizumab (PF04950615; RN316) in subjects with heterozygous familial hypercholesterolemia (SPIRE-FH); ClinicalTrials.gov Identifier: NCT01968980; https://clinicaltrials.gov/ct2/show/NCT01968 980.

100. Randomized clinical trial of bococizumab (PF-04950615; RN316) in subjects with hyperlipidemia or mixed dyslipidemia at risk of cardiovascular events (SPIRE-HR); ClinicalTrials.gov Identifier: NCT01968954; https://clinicaltrials.gov/ct2/show/ NCT01968954.

101. Randomized clinical trial of bococizumab (PF-04950615; RN316) in subjects with hyperlipidemia or mixed dyslipidemia at risk of cardiovascular events (SPIRE-LDL); ClinicalTrials.gov Identifier: NCT01968967; https://clinicaltrials.gov/ct2/ show/NCT01968967.

102. The evaluation of bococizumab (PF-04950615;RN316) in reducing the occurrence of major cardiovascular events in high risk subjects (SPIRE-1); ClinicalTrials.gov Identifier: NCT01975376; https:// clinicaltrials.gov/ct2/show/NCT01975376.

103. The evaluation of bococizumab (PF-04950615; RN316) in reducing the occurrence of major cardiovascular events in high risk subjects (SPIRE-2); ClinicalTrials.gov Identifier: NCT01975389; https://clinicaltrials.gov/ct2/show/NCT01975389.

104. Nissen SE, Stroes E, Dent-Acosta RE, et al. Efficacy and tolerability of evolocumab vs ezetimibe in patients with muscle- related statin intolerance: The GAUSS-3 randomized clinical trial. JAMA. 2016;19(315):1580-90.

105. Schwartz GG, Bessac L, Berdan LG, et al. Effect of alirocumab, a monoclonal antibody to PCSK9, on long-term cardiovascular outcomes following acute coronary syndromes: rationale and design of the ODYSSEY OUTCOMES trial. Am Heart J. 2014;168:682-9.

106. Sabatine MS, Giugliano RP, Keech A, et al. Rationale and design of the Further cardiovascular OUtcomes Research with PCSK9 Inhibition in subjects with Elevated Risk trial. Am Heart J. 2016;173:94-101.

107. Dimise EJ. GlobalData Report: Amgen's PCSK9 monoclonal antibody, evolocumab, zaps LDL-C in the TESLA and TAUSSIG clinical trials. http://healthcare.globaldata.com/ resources/expert-insights/pharmaceuticals/amgens-pcsk9-mono clonal-antibody-evolocumab-zaps-ldlc-in-the-tesla-and-taussigclinical-trials. Last accessed Jan 2016.

108. Evolocumab SmPC. http://www.ema.europa.eu/docs/enGB/ document_library/EPAR_-_Product_Information/human/ 003766/WC500191398.pdf. Last accessed Jan 2016.

109. Alirocumab SmPC. http://www.ema.europa.eu/docs/en_GB/ document_library/EPAR_-_Product_Information/human/003882/ WC500194521.pdf. Last accessed Jan 2016.

110. Panta R, Dahal K, Kunwar S. Efficacy and safety of mipomersen in treatment of dyslipidemia: a meta-analysis of randomized controlled trials. J Clin Lipidol. 2015;9:217-25.

111. Thomas GS, Cromwell WC, Ali S, et al. Mipomersen, an apolipoprotein B synthesis inhibitor, reduces atherogenic lipoproteins in patients with severe hypercholesterolemia at high cardiovascular risk: a randomized, double-blind, placebo-controlled trial. J Am Coll Cardiol. 2013;62:2178-84.

112. Stein EA, Dufour R, Gagne C, et al. Apolipoprotein B synthesis inhibition with mipomersen in heterozygous familial hypercholesterolemia: results of a randomized, double-blind, placebocontrolled trial to assess efficacy and safety as add-on therapy in patients with coronary artery disease. Circulation. 2012;126:2283-92.

113. McGowan MP, Tardif JC, Ceska R, et al. Randomized, placebocontrolled trial of mipomersen in patients with severe hypercholesterolemia receiving maximally tolerated lipid-lowering therapy. PLoS One. 2012;7:e49006.

114. Visser ME, Wagener G, Baker BF, et al. Mipomersen, an apolipoprotein B synthesis inhibitor, lowers low-density lipoprotein cholesterol in high-risk statin-intolerant patients: a randomized, double-blind, placebo-controlled trial. Eur Heart J. 2012;33:1142-9.

115. Raal FJ, Santos RD, Blom DJ, et al. Mipomersen, an apolipoprotein B synthesis inhibitor, for lowering of LDL cholesterol concentrations in patients with homozygous familial hypercholesterolaemia: a randomised, double-blind, placebocontrolled trial. Lancet. 2010;375:998-1006.

116. Raal FJ. Lomitapide for homozygous familial hypercholesterolaemia. Lancet. 2013;381:7-8.

117. Tuteja S, Duffy D, Dunbar RL, et al. Pharmacokinetic interactions of the microsomal triglyceride transfer protein inhibitor, lomitapide, with drugs commonly used in the management of hypercholesterolemia. Pharmacotherapy. 2014;34:227-39.

118. Cuchel M, Meagher EA, du Toit Theron H, et al. Efficacy and safety of a microsomal triglyceride transfer protein inhibitor in patients with homozygous familial hypercholesterolaemia: a single-arm, open-label, phase 3 study. Lancet. 2013;381:40-6.

119. Cuchel M, Bloedon LT, Szapary PO, et al. Inhibition of microsomal triglyceride transfer protein in familial hypercholesterolemia. N Engl J Med. 2007;356:148-56. 
120. van Capelleveen JC, Brewer HB, Kastelein JJ, et al. Novel therapies focused on the high-density lipoprotein particle. Circ Res. 2014;114:193-204.

121. Kastelein JJ, van Leuven SI, Burgess L, et al. Effect of torcetrapib on carotid atherosclerosis in familial hypercholesterolemia. N Engl J Med. 2007;356:1620-30.

122. Cannon CP, Shah S, Dansky HM, et al. Safety of anacetrapib in patients with or at high risk for coronary heart disease. N Engl J Med. 2010;363:2406-15.

123. Nicholls SJ, Brewer HB, Kastelein JJ, et al. Effects of the CETP inhibitor evacetrapib administered as monotherapy or in combination with statins on HDL and LDL cholesterol: a randomized controlled trial. JAMA. 2011;306:2099-109.

124. Hovingh GK, Kastelein JJ, van Deventer SJ, et al. Cholesterol ester transfer protein inhibition by TA-8995 in patients with mild dyslipidaemia (TULIP): a randomised, double-blind, placebo-controlled phase 2 trial. Lancet. 2015;386:452-60.

125. AIM-HIGH Investigators, Boden WE, Probstfield JL, et al. Niacin in patients with low HDL cholesterol levels receiving intensive statin therapy. N Engl J Med. 2011;365:2255-67.

126. Simko V, Ginter E. Understanding cholesterol: high is bad but too low may also be risky - is low cholesterol associated with cancer? Bratisl Lek Listy. 2014;115:59-65.

127. Schatzkin A, Hoover RN, Taylor PR, et al. Serum cholesterol and cancer in the NHANES I epidemiologic followup study. National Health and Nutrition Examination Survey. Lancet. 1987;2:298-301.
128. Fouchier SW, Sankatsing RR, Peter J, et al. High frequency of APOB gene mutations causing familial hypobetalipoproteinaemia in patients of Dutch and Spanish descent. J Med Genet. 2005;42:e23.

129. Singh VN, Citkowitz E. Low LDL cholesterol (hypobetalipoproteinemia). Medscape. Updated: Dec 16, 2014. http:// emedicine.medscape.com/article/121975-overview. Last accessed Jan 2016

130. Lee J, Hegele RA. Abetalipoproteinemia and homozygous hypobetalipoproteinemia: a framework for diagnosis and management. J Inherit Metab Dis. 2014;37:333-9.

131. Bonifacio A, Sanvee GM, Bouitbir J, Krähenbühl S. The AKT/ mTOR signaling pathway plays a key role in statin-induced myotoxicity. Biochim Biophys Acta. 2015;1853:1841-9.

132. Robinson JG. Statins and diabetes risk: how real is it and what are the mechanisms? Curr Opin Lipidol. 2015;26:228-35.

133. Rütti S, Ehses JA, Sibler RA, et al. Low- and high-density lipoproteins modulate function, apoptosis, and proliferation of primary human and murine pancreatic beta-cells. Endocrinology. 2009;150:4521-30.

134. Kruit JK, Kremer PH, Dai L, et al. Cholesterol efflux via ATPbinding cassette transporter A1 (ABCA1) and cholesterol uptake via the LDL receptor influences cholesterol-induced impairment of beta cell function in mice. Diabetologia. 2010;53:1110-9.

135. Besseling J, Kastelein JJ, Defesche JC, et al. Association between familial hypercholesterolemia and prevalence of type 2 diabetes mellitus. JAMA. 2015;313:1029-36. 